\title{
Best Observed Case Imputation Technique
}

National Cancer Institute

\section{Source}

National Cancer Institute. Best Observed Case Imputation Technique. NCI Thesaurus.

Code C132340.

A data imputation technique that populates analysis values with the best outcome recorded within a subject. 